\title{
Effect of Methyl Jasmonate on Morphology and Dormancy Development in Lily Bulblets Regenerated In Vitro
}

\author{
Ján Jásik, ${ }^{1,2 \dagger}$ and Geert-Jan de Klerk ${ }^{2 *}$ \\ ${ }^{1}$ Department of Plant Physiology, Comenius University, Mlynská dolina B2, 84215 Bratislava, Slovakia; ${ }^{2}$ Wageningen Tissue Culture \\ Centre, Biodiversity and Breeding, Plant Research International, P.O. Box 16, 6700 AA Wageningen, The Netherlands
}

\begin{abstract}
Scales of lily bulbs are swollen petioles. Lily scale fragments cultured in vitro regenerate bulblets consisting of scales that may or may not carry a leaf blade. The bulblets are dormant and require a cold treatment to sprout. We added the gaseous plant growth regulator methyl jasmonic acid (MeJA) in the headspace of the tissue-culture container and studied the effect on plantlet morphology (scale/ leaf-blade formation) and dormancy development in three lilies, Lilium speciosum "Rubrum No. 10," L. longiflorum "Snow Queen," and the Asiatic hybrid "Connecticut King." Methyl jasmonic acid strongly reduced leaf-blade formation in Lilium longiflorum and Connecticut King. This was a specific effect as scale formation was affected much less. The specific inhibition of leaf-blade formation was not observed in Lilium speciosum. In this lily, high concentrations of methyl jasmonic acid (MeJA) inhibited leaf-blade
\end{abstract}

and scale formation to similar extents. Methyl jasmonic acid reduced dormancy development in all three lilies, with the largest effect observed in Connecticut King. In this Asiatic hybrid, almost all bulblets that had regenerated at 300 or $1000 \mu \mathrm{l}^{-1}$ MeJA in the headspace, did not require a dormancy-breaking treatment to achieve sprouting after planting in soil. Previously, it has been found in lily that treatments that reduce leaf-blade formation promote dormancy development. The present findings with MeJA do not agree with this. In the three lilies, the various parameters that were studied-regeneration, scale weight, leaf-blade weight, and dormancy development-were very differently affected by MeJA.

Key words: Bulb formation; Dormancy development; Jasmonic acid; Lilium; Methyl jasmonate.
${ }^{\dagger}$ Present address: Department of Plant Developmental Biology, Max Planck Institute for Plant Breeding Research, Carl-von-Linné-Weg 10, D-50829 Köln, Germany

Received 3 May 2005; accepted 15 September 2005; Online publication 28 February 2006

*Corresponding author; e-mail: geertjan.deklerk@wur.nl

\section{INTRODUCTION}

Jasmonates (jasmonic acid and its derivatives) are plant growth regulators that appear to be common in higher plants. They act on the transcriptional level, and responsive genes have been identified (see for review, Creelman and Mullett 1997; 
Turner and others 2002; Devoto and Turner 2003). Many genes regulated by jasmonates participate in defense and stress responses (Reymond and others 2004; Gfeller and Farmer 2004; Pozo and others 2005).

Application of jasmonates and analysis of mutants indicate that jasmonates also have a significant role in various developmental processes (see for review Koda 1997; Devoto and Turner 2005). Jasmonates influence storage organ formation. Exogenously applied jasmonates induce or promote tuber formation in potato (Koda and others 1991), yam (Koda and Kikuta 1991; Jasik and Mantell 2000; Bazabakana and others 2003), and orchid (Debeljak and others 2002), as well as bulb formation in garlic (Ravnikar and others 1993) and narcissus (Santos and Salema 2000). The putative role of jasmonates in storage organ formation has been corroborated by reports on increased endogenous levels of jasmonates in bulb- and tuber-forming plants (Nojiri and others 1992; Helder and others 1993). These finding are of particular importance for agriculture.

Jasmonates break dormancy in apple seeds (Ranjan and Lewak 1992) but inhibit seed germination in other species (Wilen and others 1994; Kepczynski and Bialecka 1994). Depending on the concentration, jasmonates inhibit or promote sprouting in partially dormant yam microtubers (Bazabakane and others 1999). Often, abscisic acid (ABA) and jasmonate have similar effects (Parthier 1991), but in potato jasmonic acid does not reverse the reduction of dormancy development by fluridone (an inhibitor of ABA synthesis), whereas ABA does (Suttle and Hulstrand 1994). In regeneration of adventitious organs, jasmonates are inhibitory (Tampe and others 2001). Capitani and others (2005) report that methyl jasmonic acid (MeJA) promotes the formation of adventitious meristematic cell clusters in thin cell layers of tobacco but inhibits subsequent development into meristemoids and primordia. This corresponds with the promotion by MeJA of adventitious root formation in apple microcuttings early during the regenerative process, making cells more sensitive to auxins (De Klerk 2002).

Lily bulblets regenerated in tissue culture are similar to naturally produced lily bulbs: they consist of a basal plate (which is a very short stem) and scales. The scales are swollen bases of petioles and may or may not bear a leaf blade. Because the bulblets are newly formed during tissue culture, and because tissue culture conditions can be easily controlled and manipulated (for example, by adding compounds to the tissue culture medium), regen- eration of bulblets from scale segments in vitro is an excellent system to study the control of storage-organ formation. Previously, we reported that, depending on the conditions, scale formation or leafblade formation prevails: particularly at high concentrations of $\mathrm{ABA}$ or sucrose, and at high temperature, leaf-blade formation is reduced and bulbformation is promoted (Aguettaz and others 1990). Because the bulblets are dormant at harvest (12 weeks after the start of tissue culture) and require a cold treatment before planting in soil, in vitro regenerating lily bulblets also constitute an outstanding system in which to examine the regulation of dormancy development (De Klerk and Gerrits 1996). The dormancy level of bulblets also increases with the temperature during regeneration, and with the sugar and ABA concentrations (Delvallee and others 1990; Djilianov and others 1994; Kim and others 1994). These data indicate that storage organ formation and dormancy development are regulated by the same mechanisms. In the present article, we study the effect of MeJA on scale formation and dormancy development in three lily genotypes that show differences in plantlet morphology (leaf blade vs. scale formation) and dormancy development (Langens-Gerrits and others 2001).

\section{Materials ANd Methods}

\section{Plant Material and Tissue Culture}

Bulbs of Lilium speciosum Thunb. "Rubrum No. 10" (L. speciosum is one of the parents of Oriental hybrids), L. longiflorum "Snow Queen," and the Asiatic hybrid "Connecticut King" were stored after harvest at $-2^{\circ} \mathrm{C}$ until use. Scales were excised from the bulbs and surface-sterilized by immersion in $70 \%$ ethanol for $30 \mathrm{~s}$, followed by $1 \%(\mathrm{w} / \mathrm{v}) \mathrm{NaClO}+$ $0.1 \%(\mathrm{v} / \mathrm{v})$ Tween 20 for $30 \mathrm{~min}$. The scales were rinsed thoroughly with sterile water.

The method for adventitious bulb production has been described in detail by Aguettaz and others (1990). Briefly, $7 \times 7 \mathrm{~mm}$ explants were cut from scales and cultured with the abaxial side on $15 \mathrm{ml}$ of medium in $2.2-\mathrm{cm}$-diameter glass tubes. This medium was composed of MS salts (Murashige and Skoog 1962), $30 \mathrm{~g} \mathrm{l}^{-1}$ sucrose, $100 \mathrm{mg} \mathrm{l}^{-1}$ myoinositol, $\quad 0.4 \quad \mathrm{mg} \mathrm{l} \mathrm{l}^{-1}$ thiamine- $\mathrm{HCl}, \quad 0.25 \mu \mathrm{M}$ 1-naphthaleneacetic acid (NAA), and $6 \mathrm{~g} \mathrm{l}^{-1}$ agar (BBL granulated). The $\mathrm{pH}$ was adjusted to 5.8 before autoclaving. Methyl jasmonic acid was dissolved at various concentrations in $96 \%$ ethanol, and $15 \mu \mathrm{l}$ of this solution was applied on a strip of filter paper fixed in the upper part of the tubes, just below the 
lid. The tubes were closed by a cap and three layers of Parafilm. In the graphs, concentrations of MeJA in the gas phase are given as $\mu \mathrm{ll}^{-1}$. In some experiments, filter-sterilized solutions of abscisic acid (ABA), fluridone, and $\mathrm{AgNO}_{3}$ were applied. For each treatment, approximately 40 scale explants were used. Unless stated otherwise, cultures were kept at $20^{\circ} \mathrm{C}$ at $30 \mu \mathrm{Em}^{-2} \mathrm{~s}^{-1}$ for $16 \mathrm{~h}$ per day (Philips, TL33). All chemicals were obtained from Duchefa (Haarlem, The Netherlands)

\section{Assessment of Plantlet Morphology and Dormancy Status}

The bulblets that had regenerated from the explants were harvested after 12 weeks of culture unless stated otherwise. The number of bulblets, and FW (fresh weight) of leaves and bulblets were determined in the noncontaminated cultures. The contamination percentage was $5-30 \%$. The data are means of 30-40 explants. The level of dormancy was evaluated as described by Gerrits and others (1992). Briefly, for each treatment 50 bulblets were planted in steamed potting soil and kept at $17^{\circ} \mathrm{C}$ and $30 \mu \mathrm{Em}^{-2} \mathrm{~s}^{-1}$ for $16 \mathrm{~h}$ per day. To check bulb viability, 25 bulblets were cold-treated $\left(6\right.$ weeks at $\left.2^{\circ} \mathrm{C}\right)$ before planting. All treatments showed high viability (more than 90\%). Ten weeks after planting, the numbers of sprouted, dormant, and dead bulblets were recorded. In the graphs, emergence is shown as a percentage of the viable bulblets. The statistical significances of differences in sprouting percentages and means were evaluated in the $\chi^{2}$ and the Student $t$-test, respectively.

\section{RESULTS}

\section{Bulblet Morphology}

In L. longiflorum and in Connecticut King, MeJA reduced the number of regenerated bulblets per explant (Figure 1A), whereas in L. speciosum there was no inhibitory effect up to $300 \mu \mathrm{l} \mathrm{l}^{-1}$ and only $1000 \mu \mathrm{l} \mathrm{l}^{-1}$ gaseous MeJA (0.336 mg of liquid MeJA per tube) reduced regeneration slightly (Figure 1A). Methyl jasmonic acid decreased FW of leaf blades in $L$. longiflorum at all concentrations that were examined. In Connecticut King and, in particular in L. speciosum, inhibition was less (Figure 1B). In both Connecticut King and L. longiflorum, scale FW was much less affected by MeJA than leaf-blade FW (Figure 1c). This resulted at high MeJA concentrations in formation of bulblets that did not carry leaves (Figure 2).
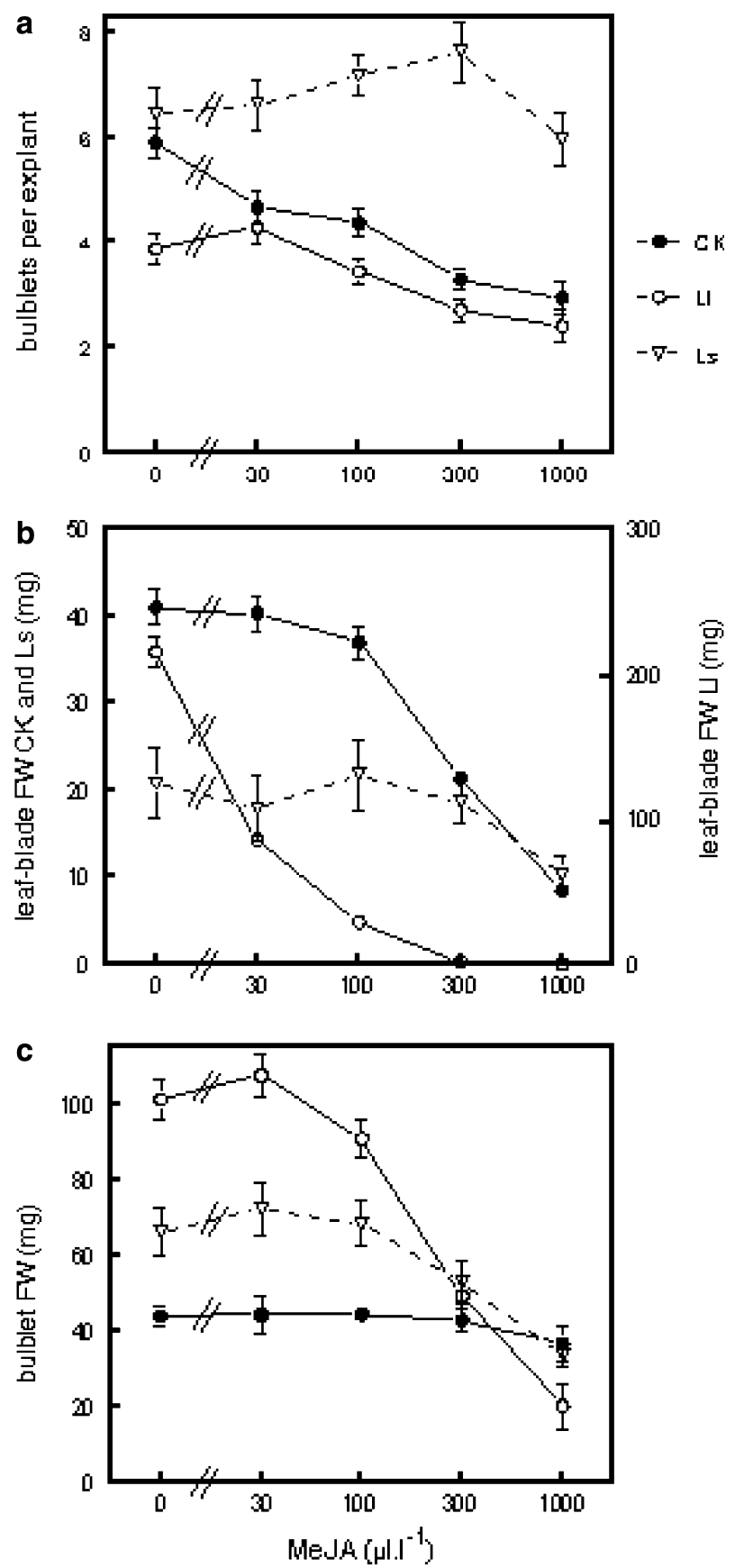

Figure 1. Effects of airborne MeJA on numbers of regenerated bulblets $(\mathbf{a})$, leaf-blade fresh weight $(\mathrm{FW})(\mathbf{b})$, and bulblet FW (c). The observations were made 12 weeks after the start of culture. Three lily genotypes were examined, viz., the Asiatic hybrid "Connecticut King" (CK), L. longiflorum "Snow Queen" (Ll), and L. speciosum "Rubrum" no. 10 (Ls). Vertical bars represent standard errors of means.

It may be that MeJA had a greater effect on leaf blades because it was added as a gas and entered leaf blades more than scales because of a larger 


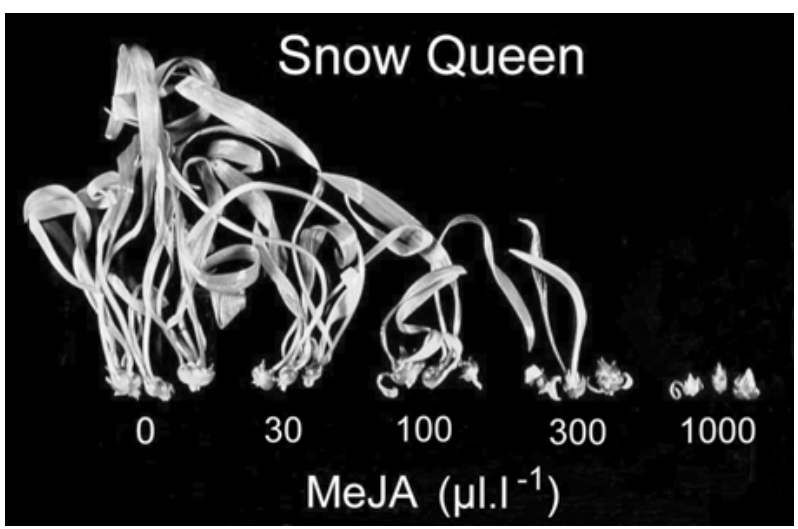

Figure 2. Morphology of bulblets regenerated in the presence of increasing levels of airborne MeJA.

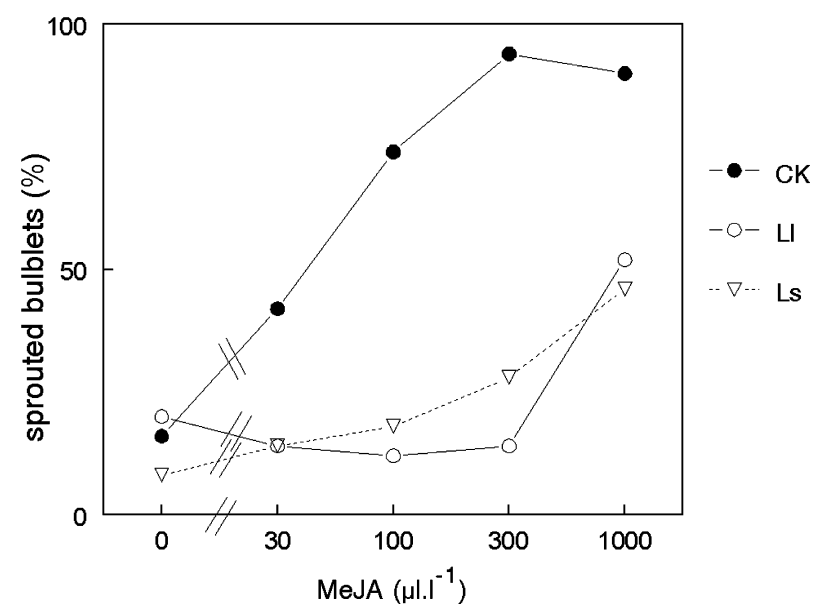

Figure 3. Effects of airborne MeJA on capacity of regenerated bulblets to sprout without a preceding cold treatment. Three lily genotypes were examined, viz., the Asiatic hybrid Connecticut King (CK), L. longiflorum Snow Queen (Ll) and L. speciosum Rubrum no. 10 (Ls). A high capacity to sprout without a preceding cold treatment indicates a low dormancy level.

number of stomata. Therefore we added MeJA in one experiment also via the medium. The doseresponse curves of MeJA added via the medium and via the atmosphere were very similar (data not shown).

In L. speciosum we also tested the effect of MeJA in combination with other factors, that is, different temperatures $\left(15,20\right.$, or $\left.25^{\circ} \mathrm{C}\right)$ and duration of culture $(8,10,12$ weeks), and the presence of ABA $(0,5$, or $25 \mu \mathrm{M})$, fluridone (an inhibitor of $\mathrm{ABA}$ synthesis [Kim and others 1994]; 0, 1, or $10 \mu \mathrm{M}$ ), or $\mathrm{AgNO}_{3}(0.5,5$, or $50 \mu \mathrm{M})$ but we did not observe any significant interaction with respect to leaf-blade or scale FW (data not shown).

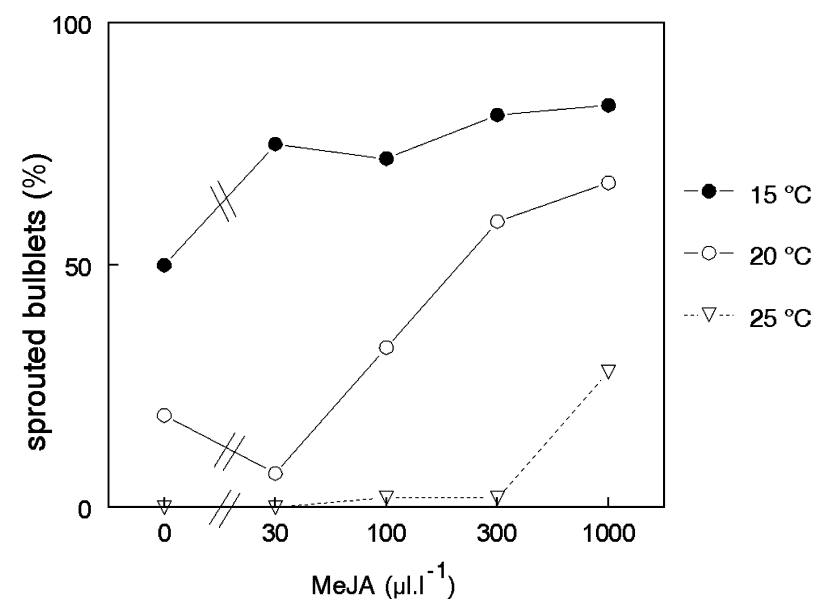

Figure 4. Effects of airborne MeJA on capacity of regenerated bulblets to sprout without a preceding cold treatment in L. speciosum. The bulblets were regenerated for 11 weeks at 15,20 or $25^{\circ} \mathrm{C}$. A high capacity to sprout without a preceding cold treatment indicates a low dormancy level.

\section{Dormancy Development}

The presence of MeJA during regeneration reduced the level of dormancy as shown by emergence after planting in soil without a preceding cold treatment: When regenerated at a high concentration of MeJA, a smaller percentage of bulblets required cold treatment. The largest effect was observed in Connecticut King. When transferred to soil, almost all bulblets of this lily hybrid regenerated at MeJA concentrations of 300 or $1000 \mu \mathrm{l} \mathrm{l}^{-1}$ and sprouted without a preceding cold treatment (Figure 3). This demonstrates that MeJA reduced dormancy development. In L. longiflorum and L. speciosum, the effects were smaller but statistically significant (in L. speciosum and in L. longiflorum $p<0.01$ at $300 \mu \mathrm{l}^{-1}$ and $1000 \mu \mathrm{l} \mathrm{l}^{-1}$, respectively).

Previously, we reported that in $L$. speciosum the dormancy level of bulblets regenerated at 15, 20, or $25^{\circ} \mathrm{C}$ is low, intermediate, or high, respectively (Aguettaz and others 1990). In L. speciosum, the effect of MeJA on dormancy development was greatest when bulblets were regenerated at $20^{\circ} \mathrm{C}$, as compared to 15 or $25^{\circ} \mathrm{C}$ (Figure 4). In bulblets regenerated at $15^{\circ} \mathrm{C}$, however, a significant effect of MeJA occurred at the low MeJA concentration of $30 \mu \mathrm{l} \mathrm{l}^{-1}$. In contrast, at $25^{\circ} \mathrm{C}$ only the highest concentration $\left(1000 \mu \mathrm{l} \mathrm{l}^{-1}\right)$ reduced dormancy development $(p<0.05)$.

In L. speciosum, dormancy develops from approximately 6 weeks up to approximately 12 weeks after the start of culture (Delvallée and others 1990). We 


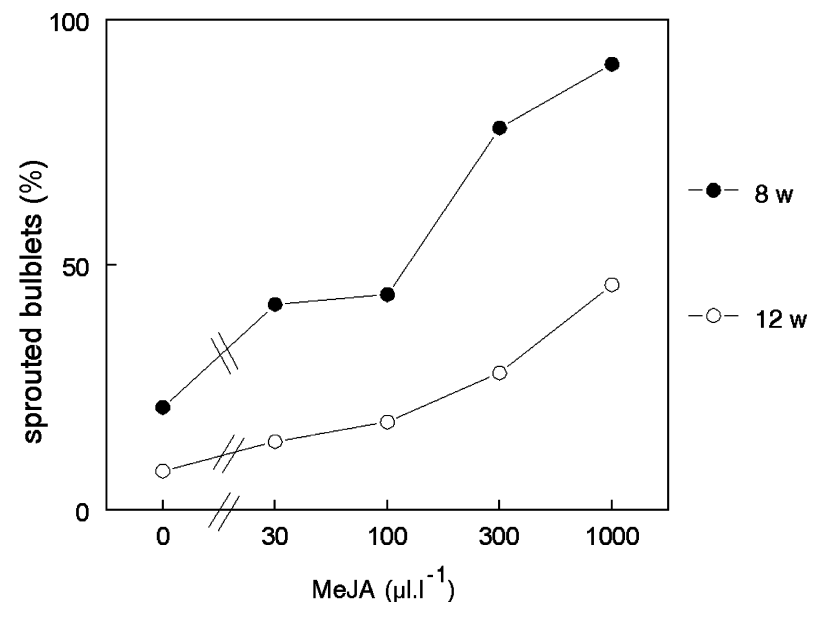

Figure 5. Effects of airborne MeJA on capacity of regenerated bulblets to sprout without a preceding cold treatment in L. speciosum. The bulblets were regenerated for either 8 or 12 weeks. A high capacity to sprout without a preceding cold treatment indicates a low dormancy level.

examined dormancy development in young, 8week-old bulblets that were not yet completely dormant. Figure 5 shows that in these young bulblets, MeJA reduced dormancy development more than in mature bulblets and that a significant effect was obtained at a low MeJA concentration $\left(30 \mathrm{Ll} \mathrm{l}^{-1}\right)$.

The data presented thus far suggest that MeJA interferes with dormancy development. The possibility cannot be excluded, however, that dormancy is induced and, after that, broken by MeJA. To check this possibility, L. speciosum bulblets regenerated at $25^{\circ} \mathrm{C}$ were soaked overnight in an aqueous MeJA solution in concentrations up to $1000 \mu \mathrm{M}$, but no influence on the dormancy status was observed (data not shown). It should be noted that a similar treatment with $\mathrm{GA}_{4+7}$ breaks dormancy completely (Gerrits and others 1992). A putative dormancy breaking effect of MeJA was also examined in another way. L. speciosum bulblets were regenerated for 12 weeks at 15,20 , or $25^{\circ} \mathrm{C}$, so that they developed various levels of dormancy. After that, we added MeJA at 100 or $1000 \mu \mathrm{l} \mathrm{l}^{-1}$ for 10 , 20 , or 30 days. In none of the treatments did we observe a significant effect of MeJA on dormancy status (data not shown).

\section{DisCussion}

\section{Inhibition of Leaf-Blade Formation}

Regeneration of lily bulblets from scale explants in vitro is a suitable system in which to study the mechanisms that regulate storage-organ formation and dormancy development (De Klerk and Gerrits 1996). The present study examines the role of a new plant growth regulator, MeJA, which has been shown to promote storage organ formation in, among others, potato, yam, and garlic (see the opening paragraphs for references).

In Connecticut King and in L. longiflorum, addition of MeJA reduced both bulb and leaf FW, but to different extents. At $1000 \mu \mathrm{ll}^{-1} \mathrm{MeJA}$, the relative bulb FW (bulb FW as a percentage of plant FW) increased from $32 \%$ to $99 \%$ in L. longiflorum and from $52 \%$ to $81 \%$ in Connecticut King. In L. speciosum, no such effect was found: The relative bulb FW was approximately $75 \%$ at all MeJA concentrations. As noted in the opening paragraphs, various authors report evidence about a regulative role of jasmonates in storage organ formation. It should be noted though that the results in the literature are not consistent. Jackson and Willmitzer (1994) failed to induce tuberization in potato by spraying with jasmonic acid (JA), even though JA had been taken up and transported within the plants. Our study on yam (Jasik and Mantell 2000) showed that tuber induction by MeJA is heavily genotype-dependent, and significant positive effects are obtained only when other conditions also favor tuber formation. Moreover, MeJA exhibits different effects in yam when applied in the medium (supporting microtuber formation) or as a vapor (suppressing microtuber formation). Our present data also suggest a role for MeJA in storage-organ formation in lily, but other interpretations are possible. It may be, for example, that MeJA has a general inhibitory effect on growth and that leaf tissue is more sensitive than scale tissue.

It has been suggested that jasmonates induce storage-organ formations via disruption and reorganization of the cytoskeleton (Koda 1997). It is also important to note that similarly to darkness and sucrose (both favor tuber/bulb formation) jasmonates suppress genes related to photosynthesis (Creelman and Mullet 1997 and references therein). Whether this action is related to the suppression of leaf-blade formation and why three different lily genotypes respond differently to the MeJA treatment requires further study.

\section{Dormancy Development}

A major finding in the present study is that MeJA inhibits dormancy development. Especially bulblets of Connecticut King regenerated with addition of MeJA and transferred to soil without an 
intermediate cold treatment, sprouted at a high rate. The short duration of the cold period required to break dormancy suggests that Connecticut King has a lower level of dormancy than $L$. speciosum (Langens-Gerrits and others 2001). Therefore the strong effect of MeJA in Connecticut King might be related to its low level of dormancy. This assumption, though unlikely, holds as L. longiflorum has a lower dormancy level than Connecticut King (Langens-Gerrits and others 2001) and shows a similar sensitivity to applied MeJA as L. speciosum (Figure 2). Data on the role of jasmonates in dormancy development in seeds and buds are almost completely absent. In seeds, abscisic acid (ABA) regulates dormancy development (see for example, Karssen and others 1983). In lily bulblets, ABA also plays such a role (Kim and others 1994). Thus, MeJA is the second hormonal factor demonstrated to have a role in dormancy development. For other hormones (auxins, cytokinins, gibberellins, ethylene), no effect in dormancy development has been established (G. J. de Klerk, unpublished data).

We observed no effect of MeJA on dormancy breaking in lily bulblets. The effects of jasmonates on the breaking of dormancy have been examined in seeds, but the results are ambiguous. On the one hand, in seeds of several species, exogenously applied jasmonates inhibited germination (Wilen and others 1994; Kepczynski and Bialecka 1994), but on the other hand, JA-like gibberellins-stimulated germination in apple (Ranjan and Lewak 1992) and Acer tataricum (Berestetzky and others 1991). According to Ranjan and Lewak (1992), like gibberellins, JA breaks dormancy by stimulation of alkaline lipase, and this could be involved in the control of mobilization of reserve lipids.

In previous studies in L. speciosum, an increase of sucrose concentration or temperature resulted in a high dormancy level (Aguettaz and others 1990; Delvallée and others 1990), and fluridone, an ABAsynthesis inhibitor, prevented dormancy development (Kim and others 1994; Djilianov and others 1994). All three factors promote bulb-scale formation and reduce leaf-blade formation. Thus, factors enhancing bulb formation also promote dormancy development. In correspondence with this, it was found that from 6 weeks after the start of tissue culture, dormancy develops, and that from that same time onward, only scales without leaf blades are formed (Delvallée and others 1990; it should be noted that during the period of generation of bulblets, continuous scales are formed, and that at 12 weeks bulblets consist of 4-5 scales). These results suggest an inverse relationship between the capacity for leaf formation and dormancy development.
The occurrence of leaves, however, does not always coincide with low dormancy. When bulblets are regenerated in darkness, leaf-blade formation is strongly inhibited, whereas there is no effect on the dormancy status (Aguettaz and others 1990). In this study we show additional evidence that scale formation and dormancy development are not strictly related: MeJA strongly inhibited leaf-blade formation, whereas dormancy development was suppressed instead of promoted.

\section{Genotype Dependence Is Different for the Various Characteristics}

We have studied the effect of applied MeJA on various parameters, viz., regeneration, plantlet FW, bulblet formation, and dormancy status, and we found significant effects of MeJA on all parameters. The extents of the effects on the various parameters differed for the various lilies, but to a dissimilar degree. For example, the effect of MeJA on the reduction of leaf $\mathrm{FW}$ was much larger in L. longiflorum than in Connecticut King, but MeJA had little effect on dormancy development in $L$. longiflorum and had a major effect in Connecticut King. These different effects in the various genotypes may be related to differences in occurrence or sensitivity of MeJA-receptors for the various processes.

\section{REFERENCES}

Aguettaz P, Paffen A, Delvallée I, Van der Linde P, de Klerk GJ. 1990. The development of dormancy in bulblets of L. speciosum generated in vitro. I. The effects of culture conditions. Plant Cell Tissue Organ Cult 22:167-172.

Bazabakana R, Wattiez R, Baucher M, Diallo B, Jaziri M. 2003. Effect of jasmonic acid on developmental morphology during in vitro tuberisation of Dioscorea alata (L). J Plant Growth Regul 40:229-237.

Berestetzky V, Dathe W, Daletskaya T, Musatenko L, Sembdner G. 1991. Jasmonic acid in seed dormancy of Acer tataricum. Biochem Physiol Pflanz 187:13-19.

Capitani F, Biondi S, Falasca G, Ziosi V, Balestrazzi A, and others. 2005. Methyl jasmonate disrupts shoot formation in tobacco thin cell layers by over-inducing mitotic activity and cell expansion. Planta 220:507-519.

Creelman RA, Mullet JE. 1997. Biosynthesis and action of jasmonates in plants. Annu Rev Plant Physiol Plant Mol Biol 48:355-381.

Debeljak N, Regvar M, Dixon KW, Sivasithamparam K. 2002. Induction of tuberisation in vitro with jasmonic acid and sucrose in and Australian terrestrial orchid, Pterostylis sanguinea. J Plant Growth Regul 36:253-260.

De Klerk GJ, Gerrits MM. 1996. Development of dormancy in tissue-cultured lily bulblets and apple shoots In: Lang GA, editor. Plant Dormancy- Physiology, Biochemistry and Molecular Biology Wallingford, CT, CAB International. pp 115-131. 
De Klerk GJ. 2002. Rooting of microcuttings: theory and practice. In Vitro Cell Dev Biol-Plant 38:415-422.

Delvallée I, Paffen A, de Klerk GJ. 1990. The development of dormancy in bulblets of Lilium speciosum generated in vitro. II. The effect of temperature. Physiol Plant 80:431-436.

Devoto A, Turner JG. 2003. Regulation of jasmonate-mediated plant responses in Arabidopsis. Ann Bot 92:329-337.

Devoto A, Turner JG. 2005. Jasmonate-regulated Arabidopsis stress signalling network. Physiol Plant 123:161-172.

Djilianov D, Gerrits MM, Ivanova A, van Onckelen HAvan, de Klerk GJ. 1994. ABA content and sensitivity during the development of dormancy in lily bulblets regenerated in vitro. Physiol Plant 91:639-644.

Gerrits MM, Kim KS, de Klerk GJ. 1992. Hormonal control of dormancy in bulblets of Lilium speciosum cultured in vitro. Acta Hortic 325:521-527.

Gfeller A, Farmer EE. 2004. Keeping the leaves green above us. Science 306:1515-1516.

Helder H, Miersch O, Vreugdenhil D, Sembdner G. 1993. Occurrence of hydroxylated jasmonic acids in leaflets of Solanum demissus. Physiol Plant 88:647-653.

Jackson SD, Willmitzer L. 1994. Jasmonic acid spraying does not induce tuberisation in short-day-requiring potato species kept in non-inducing conditions. Planta 194:155-159.

Jasik J, Mantel SH. 2000. Effects of jasmonic acid and its methylester on in vitro microtuberisation of three food yam (Dioscorea) species. Plant Cell Rep 19:863-867.

Karssen CM, Brinkhorst-van der Swan DLC, Breekland AE, Koornneef M. 1983. Induction of dormancy during seed development by endogenous abscisic acid: Studies on abscisic acid deficient genotypes of Arabidopsis thaliana (L). Heynh Planta 157:158-165.

Kepczynski J, Bialecka B. 1994. Stimulatory effect of ethephon, ACC, gibberellin A-3 and A-4+7 on germination of MeJA inhibited Amaranthus caudatus L. seeds. J Plant Growth Regul 14:211-216.

Kim K-S, Davelaar E, de Klerk GJ. 1994. ABA controls dormancy development and bulb formation in lily plantlets regenerated in vitro. Physiol Plant 90:59-64.

Koda Y. 1997. Possible involvement of jasmonates in various morphogenic events. Physiol Plant 100:639-646.
Koda Y, Kikuta Y. 1991. Possible involvement of jasmonic acid in tuberization of yam plants. Plant Cell Physiol 32:629-634.

Koda Y, Kikuta Y, Tazaki H, Tsujino Y, Sakamura S, and others. 1991. Potato tuber-inducing activities of jasmonic acid and related compounds. Phytochemistry 30:1435-1438.

Langens-Gerrits MM, Nashimoto S, Croes AF, Klerk GJ de . 2001. Development of dormancy in different lily genotypes regenerated in vitro. J Plant Growth Regul 34:215-222.

Murashige T, Skoog F. 1962. A revised medium for rapid growth and bioassays with tobacco tissue cultures. Physiol Plant 95:814-821.

Nojiri H, Yamane H, Seto H, Yamaguchi I, Murofushi N, and others. 1992. Qualitative and quantitative analysis of endogenous jasmonic acid in bulbing and non-bulbing onion plants. Plant Cell Physiol 33:1225-1231.

Parthier B. 1991. Jasmonates, new regulators of plant growth and development: many facts and few hypotheses on their action. Bot Acta 104:446-454.

Pozo MJ, Van Loon LC, Pieterse CM. 2005. Jasmonates-signals in plant-microbe interaction. J Plant Growth Regul 23:211222.

Ranjan R, Lewak S. 1992. Jasmonic acid promotes germination and lipase activity in non-stratified apple embryos. Physiol Plant 86:335-339.

Ravnikar M, Zel J, Plaper I, Scapan A. 1993. Jasmonic acid stimulates shoot and bulb formation of garlic in vitro. J Plant Growth Regul 12:73-77.

Santos I, Salema R. 2000. Promotion by jasmonic acid bulb formation in shoot cultures of Narcissus triandus. J Plant Growth Regul 30:133-138.

Suttle JC, Hultstrand JF. 1994. Role of endogenous abscisic acid in potato microtuber dormancy. Plant Physiol 105:891-896.

Tampe PA, Reid DM, Thorpe TA. 2001. Jasmonic acid inhibition of in vitro shoot organogenesis in Pinus radiata cotyledons. J Plant Physiol 158:607-611.

Turner JG, Ellis C, Devoto A. 2002. The jasmonate signal pathway. Plant Cell 14:S153-S164.

Wilen RW, Ewan BE, Gusta LV. 1994. Interaction of ABA and jasmonic acid on the inhibition of seed germination and the induction of freezing tolerance. Can J Bot 72:1009-1017. 